\title{
The composition of endolithic communities in gypcrete is determined by the specific microhabitat architecture
}

\author{
María Cristina Casero ${ }^{1}$, Victoria Meslier ${ }^{2, a}$, Jocelyne DiRuggiero ${ }^{2}$, Antonio Quesada $^{3}$, Carmen Ascaso ${ }^{1}$, \\ Octavio Artieda ${ }^{4}$, Tomasz Kowaluk ${ }^{5}$, and Jacek Wierzchos ${ }^{1}$ \\ ${ }^{1}$ Departamento Biogeoquímica y Ecología Microbiana, Museo Nacional de Ciencias Naturales, CSIC, Madrid, 28006, Spain \\ ${ }^{2}$ Department of Biology and Department of Earth and Planetary Sciences, Johns Hopkins University, \\ Baltimore, MD 21218, USA \\ ${ }^{3}$ Departamento de Biología, Universidad Autónoma de Madrid, Madrid, 28014, Spain \\ ${ }^{4}$ Departamento de Biología Vegetal, Ecología y Ciencias de la Tierra, Universidad de Extremadura, Plasencia, 06006, Spain \\ ${ }^{5}$ Institute of Metrology and Biomedical Engineering, Faculty of Mechatronics, Warsaw University of Technology, \\ 02-525 Warsaw, Poland \\ a now at: MetaGenoPolis, Jouy-en-Josas, France
}

Correspondence: María Cristina Casero (mcristina.casero@mncn.csic.es) and Jacek Wierzchos (j.wierzchos@mncn.csic.es)

Received: 25 June 2020 - Discussion started: 3 August 2020

Revised: 24 November 2020 - Accepted: 3 December 2020 - Published: 10 February 2021

\begin{abstract}
Endolithic microhabitats have been described as the last refuge for life in arid and hyper-arid deserts where life has to deal with harsh environmental conditions. A number of rock substrates from the hyper-arid Atacama Desert, colonized by endolithic microbial communities such as halite, gypsum crusts, gypcrete, calcite, granite and ignimbrite, have been characterized and compared using different approaches. In this work, three different endolithic microhabitats are described, each one with a particular origin and architecture, found within a lithic substrate known as gypcrete. Gypcrete, an evaporitic rock mainly composed of gypsum $\left(\mathrm{CaSO}_{4} \cdot 2 \mathrm{H}_{2} \mathrm{O}\right)$ and collected in the Cordón de Lila area of the desert (Preandean Atacama Desert), was found to harbour cryptoendolithic (within pore spaces in the rock), chasmoendolithic (within cracks and fissures) and hypoendolithic (within microcave-like pores in the bottom layer of rock) microhabitats. A combination of microscopy investigation and high-throughput sequencing approaches were used to characterize the endolithic communities and their habitats at the microscale within the same piece of gypcrete. Microscopy techniques revealed differences in the architecture of the endolithic microhabitats and the distribution of the microorganisms within those microhabitats. Cyanobacteria and Proteobacteria were dominant in the endolithic communities, of which the hypoendolithic community was the least diverse
\end{abstract}

and hosted unique taxa, as a result of less access to sun radiation. These results show, for the first time, that the differences in the architecture of a microhabitat, even within the same piece of a lithic substrate, play an essential role in shaping the diversity and composition of endolithic microbial communities.

\section{Introduction}

The statement developed by Lourens Gerhard Marinus BaasBecking (Baas-Becking, 1934) that "everything is everywhere but the environment selects", which established the most referred principle for microbial biogeography, remains in discussion regarding the first half of the statement ("everything is everywhere") (de Wit and Bouvier, 2006; O'Malley, 2008; Bass and Boenigk, 2011; Fontaneto and Hortal, 2012; van der Gast, 2015). Regarding the second half of the statement ("but the environment selects"), extreme environments present some of the most plausible scenarios since they are inhabited only by microorganisms that can survive and/or thrive in their respective physical or geochemical extremes such as temperature, solar radiation, pressure, desiccation or pH (Rothschild and Mancinelli, 2001). 
Hyper-arid deserts, where the aridity index is lower than 0.05 (Nienow, 2009), constitute the most extreme deserts on Earth, and they usually combine a series of simultaneous stress conditions such as water limitation, extreme high and low temperatures, scarcity of organic carbon, high solar radiation, and osmotic stress (Pointing and Belnap, 2012). While these environments are considered polyextreme, they are inhabited by microbiota able to survive under such conditions. Hence, polyextreme environments are excellent microbial ecosystem models to study adaptive mechanisms to environmental stress. The Atacama Desert (northern Chile) is perhaps the most challenging polyextreme environment on Earth and the most barren region imaginable, with scarce precipitation events (McKay et al., 2003; Wierzchos et al., 2012a) and extremely low mean annual relative humidity (RH) (Azua-Bustos et al., 2015). Further, this desert holds another world record: the highest surface ultraviolet radiation (UV), photosynthetic active radiation (PAR) and annual mean surface solar radiation (Cordero et al., 2018) in the Chilean Coastal Range and Andes sites.

In this inhospitable polyextreme desert, microbial life has been found in different lithic habitats such as epilithic (on rocks) (Wierzchos et al. 2011), hypolithic (under rocks) (Azua-Bustos et al., 2012) and endolithic (inside rocks) microhabitats (reviewed by Wierzchos et al., 2018, 2012b). Three different locations of these endolithic habitats have been described within rocks of the Atacama Desert: cryptoendolithic (occupying pore spaces in the rock), chasmoendolithic (living within cracks and fissures in the rock) and hypoendolithic (living inside pores in the bottom part of the rock). Endolithic colonization can be viewed as a stress avoidance strategy whereby the overlying mineral substrate provides protection from incident lethal UV and PAR levels, and it also offers enhanced moisture availability (Walker and Pace, 2007; Wierzchos et al., 2012b). These microbial communities, regardless of the position they occupy in the rock or the type of rock, are supported by oxygenic phototrophic primary producers supporting a diversity of heterotrophic microorganisms (reviewed in Wierzchos et al., 2018). Molecular and microscopy characterization of these endolithic microbial communities shows that, overall, these communities are dominated by Cyanobacteria, mostly from genus Chroococcidiopsis that is extremely resistant to ionizing radiation and desiccation (Meslier et al., 2018; Crits-Christoph et al., 2016; Billi et al., 2000; Cockell et al., 2005), as well as members from genera Gloeocapsa (Crits-Christoph et al., 2016) and Halothece (de los Ríos et al., 2010; Robinson et al., 2015 and Uristkyi et al., 2019) and phyla Actinobacteria, Proteobacteria, Chloroflexi, Bacterioidetes and Euryarchaeota (Meslier et al., 2018). In gypcrete and gypsum crust from the Preandean Atacama Desert (Casero et al., 2020), previous studies reported endolithic communities dominated by the phyla Cyanobacteria (36\%-83\%), Actinobacteria (10\%-25\%) and Proteobacteria (13\%-30\%) (Wierzchos et al., 2015; Dong et al., 2007; and Meslier et al., 2018; reviewed in Casero et al., 2020); however, these studies did not differentiate between microhabitats, even though the occurrence of different endolithic microhabitats in gypcrete had already been described (Wierzchos et al., 2015).

This work addresses the impact of microhabitat architecture on the diversity and composition of gypcrete endolithic microbial communities (EMCs). The concept of rock architecture was introduced by Wierzchos et al. (2015) for colonized gypcrete substrate and encompasses the internal structures of rock with all elements that are essential for microbial life. Microhabitat architecture allows for perceiving the rock interior from the existence of porous spaces of different sizes and also the solid structures that divide and support these spaces. All these components and elements are interrelated and influence one another, thus fulfilling a requisite: they might shape a suitable architecture to hold microbial life.

The study is based on the hypothesis that the different architectures of endolithic microhabitats involve small-scale differences in the micro-environmental conditions, which in turn determine the distribution of organisms in each community. The hypothesis is tested here for the first time by using a multidisciplinary approach combining microscopy and molecular tools for their characterization. The microscale dimensions and differential diversity distribution in this unique environment have led us to coin the new term "microbiogeography".

\section{Experimental procedures}

\subsection{Site description and sampling}

Colonized rocks were collected in the Atacama Desert in December 2015 from the Monturaqui area (MTQ) (GPS coordinates: $23^{\circ} 57^{\prime} \mathrm{S}, 68^{\circ} 10^{\prime} \mathrm{W}$; $2868 \mathrm{~m}$ a.s.l.) located in an $\mathrm{N}-$ S-trending depression of the Cordón de Lila range. The area experiences a pronounced rain shadow effect by the western slope of the central Andes from $15^{\circ}$ to $23^{\circ} \mathrm{S}$ (DiRuggiero et al., 2013; Wierzchos et al., 2015). In order to study endolithic communities that inhabit the same piece of a lithic substrate, we sampled gypcrete pieces that harboured at least two of the three endolithic microhabitats of interest, that were collected within a $50 \mathrm{~m}^{2}$ area. All samples were packed in sterile bags and stored at room temperature in dry and dark conditions before further processing.

\subsection{Microclimate data}

Microclimate data (Meslier et al., 2018) were recorded using an Onset $\mathrm{HOBO}^{\circledR}$ micro weather station and data logger (H21-USB), as previously described by Wierzchos et al. (2015). Air temperature $\left(T\right.$ in $\left.{ }^{\circ} \mathrm{C}\right)$, air relative humidity (RH in \%) and photosynthetically active radiation (PAR in $\mu \mathrm{mol}$ photons $\mathrm{m}^{-2} \mathrm{~s}^{-1}$ ) were recorded from January 2011 to 
February 2013 (22 months) (Wierzchos et al., 2015). Rainfall data were obtained from DiRuggiero et al. (2013). Thermal measurements of the gypcrete surface were acquired at zenith time at $20 \mathrm{~cm}$ distance from the substrate. Thermal images were taken using a thermal infrared camera $\left(\right.$ FLIR $^{\circledR}$ E6, FLIR Systems, Oregon, USA) whose technical specifications are $\pm 2{ }^{\circ} \mathrm{C}$ or $\pm 2 \%$ of reading; $<0.06^{\circ} \mathrm{C}$ pixel sensitivity with a resolution of $160 \times 120$ pixels. Calibration of the FLIR camera for measurements of gypcrete surface temperature was performed by introducing the emissivity value of 0.92 .

\subsection{Microscopy analyses}

Colonized gypcrete samples were processed for scanning electron microscopy in backscattered detection mode (SEMBSE) according to methods described by Wierzchos and Ascaso (1994) and Wierzchos et al. (2011). Light microscopy (LM) in differential interference contrast (DIC) mode was used to examine cell aggregates gently isolated from the cryptoendolithic, chasmoendolithic and hypoendolithic microhabitats as well as on cyanobacterial isolates cultured from those microhabitats. The samples were examined using an Axio Imager M2 microscope (Carl Zeiss, Germany) in DIC mode equipped with Apochrome $63 \times, n=1.4$ oil immersion objective.

\subsection{Computed tomography (CT) scan analysis}

Micro-CT scans were run on pieces of gypcrete with an Xray computed tomography system (CT scan) - HMXST 225 micro-CT system (Nikon Metrology, Tring, UK) to observe volume, bulk density and variations in internal density. For volume and bulk density measurements, a Nikon X-Tek CTscan device was used, with an X-ray peak voltage of $146 \mathrm{kV}$ and current of $65 \mathrm{~mA}$, collecting 1583 sections at $1000 \mu \mathrm{s}$ on average from four frames. The system operates with an Xray tube and added filtration $(0.875 \mathrm{~mm} \mathrm{Cu})$ to reduce beam hardening. Three-dimensional viewing and analyses of the obtained X-ray sections were performed by VG Studio Max Version 2.2 software. The auto-threshold feature determined the greyscale intensity for 3D surface segmentation and subsequent analysis.

\subsection{Cyanobacteria isolation and characterization and DNA extraction procedures from isolates}

Biological material removed from endolithic colonization zones of gypcrete was transferred to different BG11 1.5\% agar plates (purified agar, Condalab, Spain). All samples were incubated in a growth chamber at $28 \pm 2{ }^{\circ} \mathrm{C}$ with illumination of $20 \mu \mathrm{mol}$ photons $\mathrm{m}^{-2} \mathrm{~s}^{-1}$ by cool white $40 \mathrm{~W}$ fluorescent tubes (Philips). After incubation for $15 \mathrm{~d}$, visible cyanobacterial growth appeared. Colonies were isolated by repeated plating on $0.8 \%$ agar with BG11 medium (Rippka et al., 1979), and successfully isolated colonies were trans- ferred to liquid BG11 medium. Culture material from each strain $(2 \mathrm{~mL})$ was harvested during exponential growth and centrifuged $(10000 \mathrm{~g}, 5 \mathrm{~min})$. Genomic DNA was extracted from the cell pellet using the UltraClean DNA isolation kit (Mo Bio Laboratories, Solana Beach, CA, USA). The 16S rRNA was amplified using primers PA (Edwards et al., 1989) and B23S (Lepère et al., 2000); PCR and sequencing were performed as described in Casero et al. (2014).

\subsection{DNA extraction procedures from natural samples, 16S rRNA gene library preparation and sequencing}

Three individual rocks harbouring at least two of the three endolithic microhabitats were processed, which resulted in 11 samples, including technical replicates: cryptoendolithic $(n=2)$, chasmoendolithic $(n=6)$ and hypoendolithic $(n=$ $3)$. Colonization zones were scraped and ground for DNA extraction. To avoid contamination between samples from different microhabitats, the scraping of material was carried out in the following way: due to the possible proximity of both chasmoendolithic and cryptoendolithic microhabitats, on the top of the rock, chasmoendolithic colonization zones more distant from cryptoendolithic colonization zones were selected. In addition, material from each of them was scraped by avoiding the edges, so material from different microhabitats could not be mixed. In the case of the samples coming from hypoendolithic samples, the distance from the other two microhabitats allowed their full scraping.

This DNA extraction was performed using $0.3 \mathrm{~g}$ of samples and the UltraClean DNA isolation kit (Mo Bio Laboratories, Solana Beach, CA, USA) including a three-cycle step of freezing $0.3 \mathrm{~mL}$ aliquots of sample suspended in buffer, breaking them down by using an adapted drill and melting in $60^{\circ} \mathrm{C}$ water bath, as described in Loza et al. (2013) and Becerra-Absalón et al. (2019). A two-step PCR strategy was used to prepare the sequencing libraries of endolithic microbial communities, as previously described (Robinson et al., 2015). DNA was amplified using primers $338 \mathrm{~F}$ and 806R (V3-V4 hypervariable region) barcoded for multiplexing; amplicons from two PCR runs were pooled after the first step. Illumina paired-end sequencing $(2 \times 250 \mathrm{bp})$ was performed using the MiSeq platform at the Johns Hopkins Genetic Resources Core Facility (GRCF).

\subsection{Computational analysis}

After demultiplexing and barcode removal, sequence reads with Phred score $<20$ and length $<100 \mathrm{bp}$ were discarded using the Sickle trimming tool (Joshi and Fass, 2011), representing only $2 \%$ of the initial reads count. The Qiime package (v1.6.0) was used to further process the sequences (Caporaso et al., 2010), and diversity metrics were calculated based on operational taxonomic units (OTUs) at the $0.03 \%$ cut-off against the Ribosomal Database Project (RDP) release 11 (Cole et al., 2014). The resulting OTU table was 


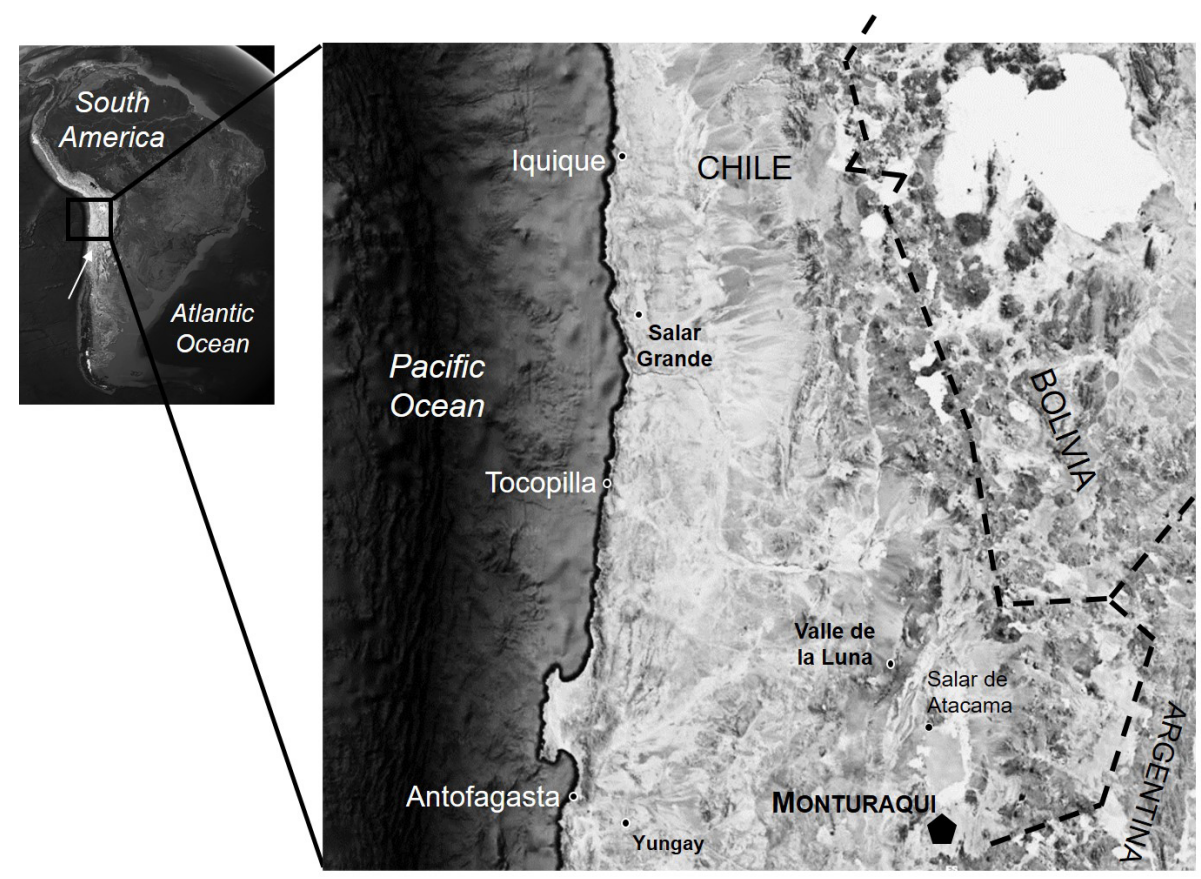

Figure 1. Sampling location in the Atacama Desert. Monturaqui area: MTQ (black diamond). (@ Google Earth, image providers: Landsat/Copernicus).

filtered for the rare OTUs (total abundance across all samples below $1 \%$ ), representing $40 \%$ of the initial count (1511 OTUs).

\subsection{Phylogenetic analysis}

Sequences of 16S rRNA genes from cyanobacterial OTUs that showed significant differences in their relative abundance between endolithic microhabitats and 16S rRNA gene sequences from cyanobacterial isolates were aligned with sequences obtained from the US National Center for Biotechnology Information (NCBI) GenBank using the Clustal W 1.4 software (Thompson et al., 1994). The 16S rRNA gene sequences from GenBank were selected using the NCBI MegaBlast tool (http://blast.ncbi.nlm.nih.gov/ Blast.cgi, last access: 28 August 2018). The final alignment length was $400 \mathrm{bp}$. Phylogenetic trees of each of the genes were constructed in MEGA 7.0 using the maximum likelihood (ML) method (Kumar et al., 2016). The best-fitting evolutionary model, chosen following BIC (Bayesian inference criterion) in MEGA 7.0, was the Kimura two-parameter model (Kimura, 1980) for 16S rRNA genes. One-thousand bootstrap replicates were performed for all trees.

\section{Results}

We combined microclimate measurements, microscopy analyses and high-throughput culture-independent molecular data to identify the effect of micro-biogeography and the fac- tors underlying the structure and composition of microbial assemblages of gypcrete endolithic microhabitats from the hyper-arid Atacama Desert.

\subsection{Sampling site}

Gypcrete samples were collected from the Monturaqui area (MTQ), located in the Preandean Depression of the Atacama Desert (Casero et al., 2020) (Fig. 1) in December 2015. Climate data recorded over a period of 22 months described a mean air temperature of about $15^{\circ} \mathrm{C}$, with strong amplitude between minima and maxima (from -4.7 to $49.3^{\circ} \mathrm{C}$ ) and average diurnal PAR of $\sim 1000 \mu \mathrm{mol}$ photons $\mathrm{m}^{-2} \mathrm{~s}^{-1}$ with a maximum of $2553.7 \mu \mathrm{mol}$ photons $\mathrm{m}^{-2} \mathrm{~s}^{-1}$, providing evidence for the extremely intense solar irradiance found in this region (Cordero et al., 2014). This area experiences extremely dry conditions, with an average air RH of about $20 \%$ with frequent lows of $1 \%$ and precipitation extremely scarce with mean annual values of $24.5 \mathrm{~mm}$ (Wierzchos et al., 2015). Gypcrete surface temperature examined with a thermal infrared camera revealed a maximum temperature of $68^{\circ} \mathrm{C}$

\subsection{Micromorphology of gypcrete}

CT-scan images provided a 3D spatial representation of pore shapes and their distribution inside the gypcrete rock (Fig. 2). The pores revealed capillary-like micromorphology that exhibits a vertical orientation as is shown in both the top and lateral views. Detailed 3D images pointed to the apparent 


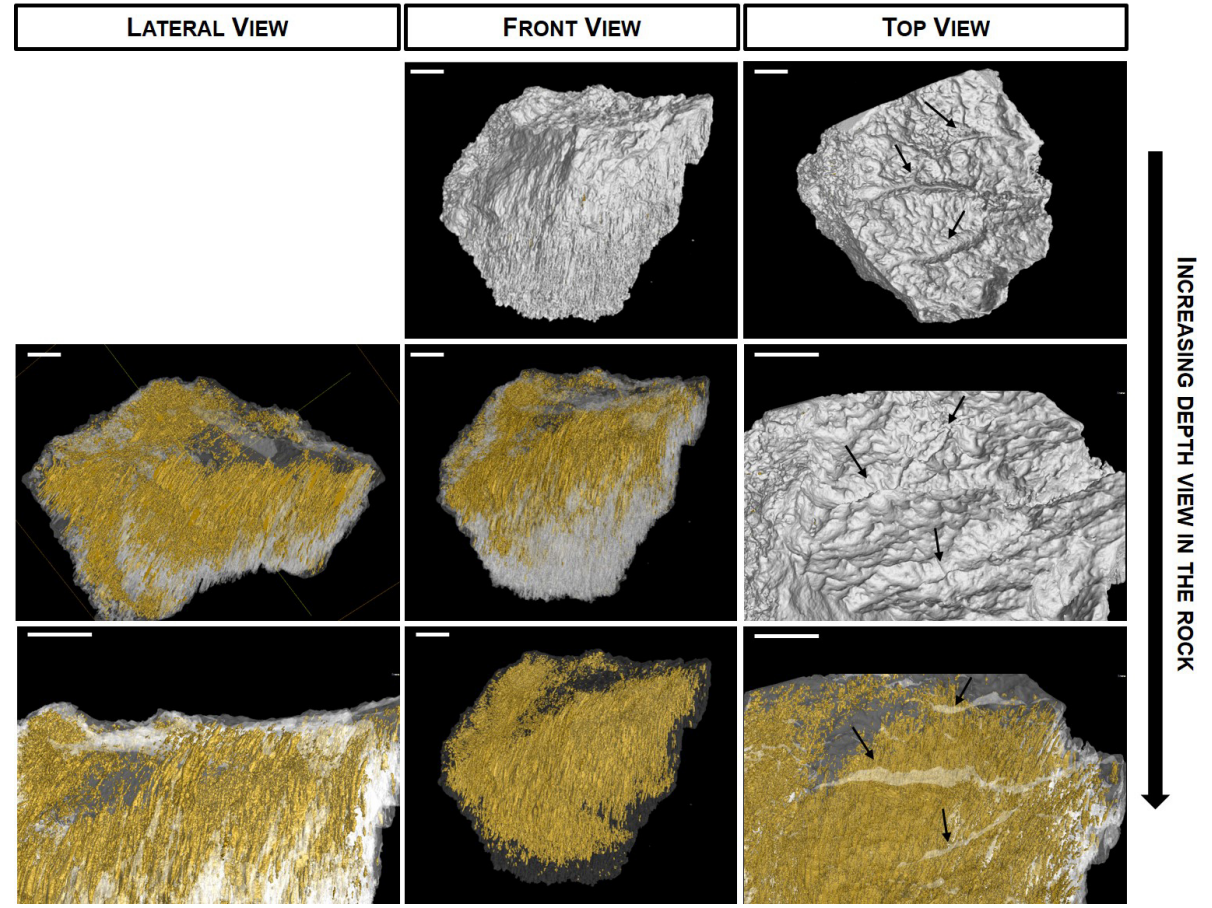

Figure 2. CT-scan images of a colonized piece of gypcrete. The 3D reconstruction of a gypcrete sample with the spatial distribution of pores (yellow colour) and complete reconstructions of the scanned volume (grey colour) on lateral, front and top views of gypcrete. Porous micromorphology is capillary-shaped in the vertical direction due to movement of the water by gravity. Arrows in top-view images point to the deepest cracks. Scale bars are $1 \mathrm{~cm}$.

absence of connectivity with the surface of most of the pores (Fig. 2). However, the presence of this connectivity cannot be discarded due to the limited resolution of the CT-scan technique and the conditions of acquisition. Moreover, CT-scan images of the gypcrete surface reveal microrill weathering features (DiRuggiero et al., 2013) due to the dissolution of gypsum after scarce rains (Supplement Video S1).

\subsection{Endolithic microhabitats}

Cross sections of the gypcrete rocks reveal the presence of three clearly differentiated microhabitats where a significant heterogeneity in micromorphology and structure was found (Fig. 3). The cryptoendolithic colonization zone is close to the compact gypcrete surface layer (up to $5 \mathrm{~mm}$ depth). Within cryptoendolithic microbial communities, two characteristic pigmented layers are distinguished. The observed orange colour belongs to microorganisms with a high carotenoid content closest to the gypcrete surface. The green colour layer beneath the orange layer belongs to microorganisms with chlorophyll and phycobiliprotein content. The presence of these pigments was previously reported by Wierzchos et al. (2015) and Vítek et al. (2016) (Fig. 3 A1). The chasmoendolithic colonization zone reaches a deeper (up to $8 \mathrm{~mm}$ depth) position in the substrate and is directly connected to the surface (Fig. 3 B1). Finally, the hypoen- dolithic colonization zone is located close to the compact bottom gypcrete crust, shaped like microcaves (Fig. 3 C1).

Cyanobacteria were found in the cryptoendolithic habitat among lenticular gypcrete crystals, filling up vertically elongated pores, and aggregated around sepiolite nodules (Fig. 3 A2-A3), a clay mineral with high water retention capacity, previously identified in gypcrete by Wierzchos et al. (2015). SEM-BSE images also revealed dense arrangements of cyanobacterial cells embedded in concentric sheets of exopolysacharides (EPS) (Fig. 3 A3). By contrast, the microbial assemblages inhabiting the chasmoendolithic and hypoendolithic microhabitats were coating the walls of the cracks and caves previously described (Fig. 3 B2, B3, C2, C3). Detailed SEM-BSE images (Fig. 3 A3-C3) and LM images (Fig. 3 A4-C4) of each microhabitat showed mainly Cyanobacteria with different sizes and morphology accompanied by heterotrophic bacteria.

\subsection{Cyanobacterial isolates from endolithic microhabitats}

A total of 12 cyanobacterial strains were isolated from the three different endolithic microhabitats (Table S1): three from cryptoendolithic, three from chasmoendolithic and six from hypoendolithic. The cyanobacterial strains were identified, following Komárek et al. (2014), as Chroococcidiopsis sp. (UAM800, UAM801, UAM802, UAM805, UAM808, 

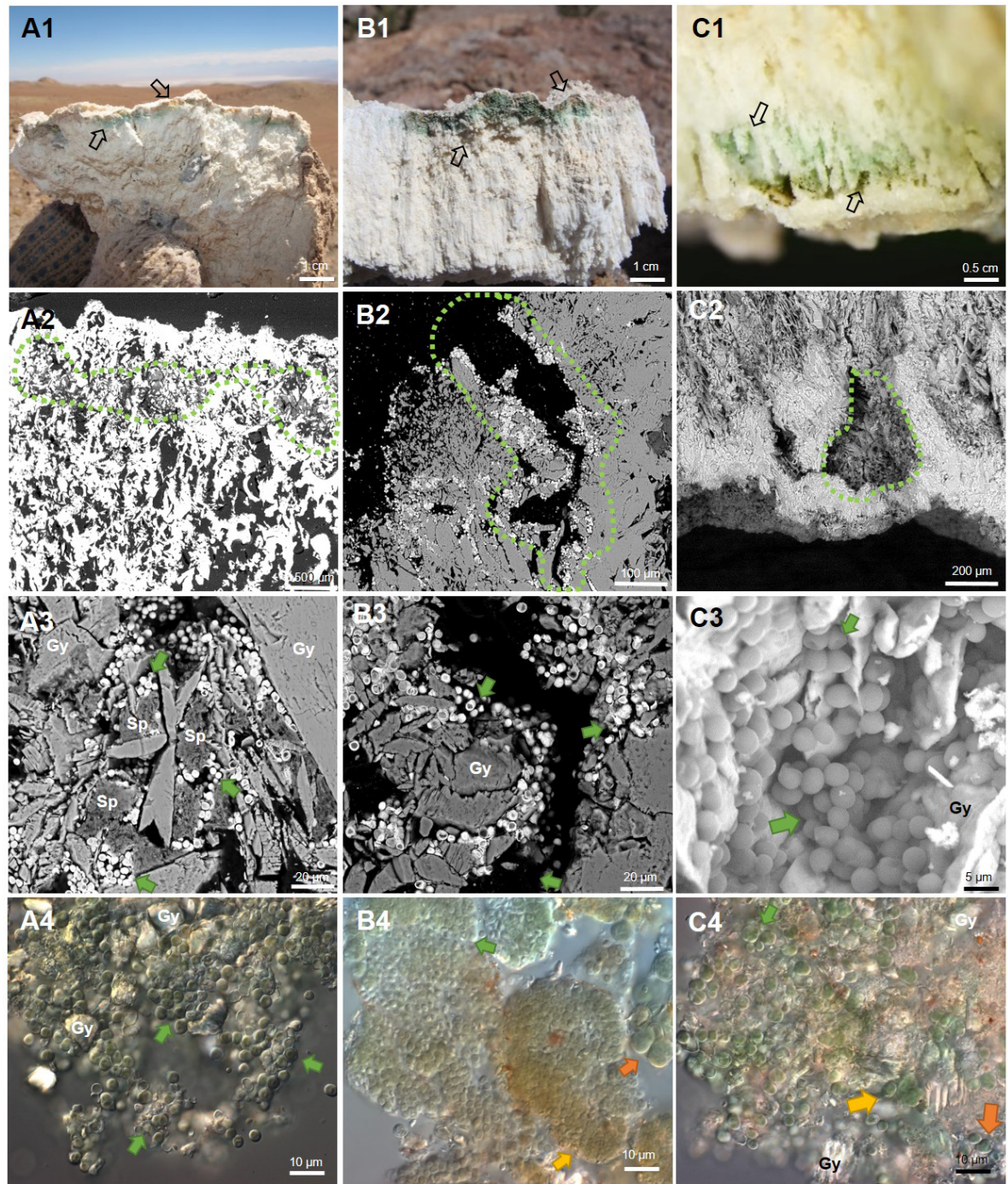

Figure 3. Characterization of endolithic colonization zones. Series A: cryptoendolithic; series B: chasmoendolithic; series C: hypoendolithic. Series 1: macro images of gypcrete cross sections of colonized zones; series 2 and 3: SEM-BSE images of gypcrete cross sections of colonized zones; series 4: LM-DIC images of scrapped Cyanobacteria from gypcrete. Series 1: black arrows indicate green and orange coloured endolithic colonization zones of $5 \mathrm{~mm}$ thickness in A1 (CR), $8 \mathrm{~mm}$ thickness in B1 beneath the surface $(\mathrm{CH})$ and $5-9 \mathrm{~mm}$ thickness in $\mathrm{C} 1$ above bottom gypsum crust (HE). Series 2: CR, CH and HE microhabitats with aggregates of endolithic microbial communities surrounded by the dotted green lines, inside the pores of gypcrete; A2 is under a white dense surface crust; B2 is inside the cracks of gypcrete, and C2 is inside the microcaves of gypcrete at the bottom of the rock. Series 3: green arrows point to aggregates of Cyanobacteria among gypcrete (Gy) crystals (A3, B3), surrounded by sepiolite (Sp), nodules (A3) and on the gypcrete (Gy) walls (C3). Series 4: aggregates of different morphotypes of cyanobacteria, shown by green, yellow and orange arrows, and gypcrete crystals (Gy).

UAM809, UAM810, UAM811), Gloeocapsa sp. (UAM803, UAM804) and Gloeocapsopsis sp. (UAM806, UAM807).

\subsection{Structure and composition of endolithic communities}

High-throughput sequencing of 16S rRNA gene amplicons across 11 samples and three microhabitats resulted in a total of $385440 \mathrm{~V} 3-\mathrm{V} 4$ small subunit (SSU) rDNA reads, with an average number of paired-end reads per sample of
$35040 \pm 6288$ and an average length of $456 \pm 11 \mathrm{bp}$. Diversity metrics, calculated from OTUs clustered at $97 \%$, revealed no significant differences between microhabitats in terms of alpha diversity (Table 1).

A total of 11 bacterial phyla with a relative abundance $>0.1 \%$ were found across all microhabitats. Of these, only seven had a relative abundance over $1 \%$ of sequences across the different microhabitats (Fig. 4). Cyanobacteria, Proteobacteria, Actinobacteria and Gemmatimonadetes were the most abundant phyla, representing $82 \%-83 \%$ of the total 
Table 1. Diversity estimates of microbial communities in the endolithic microhabitats of gypcrete.

\begin{tabular}{llrrr}
\hline Microhabitats & & $\begin{array}{r}\text { Chao } \\
(1984)\end{array}$ & $\begin{array}{r}\text { OTU } \\
\text { richness }\end{array}$ & $\begin{array}{r}\text { Shannon } \\
(1948)\end{array}$ \\
\hline Cryptoendolithic & Avg & 583.8 & 430 & 6.3 \\
& SD & 43.2 & 38 & 0.2 \\
\hline Chasmoendolithic & Avg & 574.9 & 419 & 6.1 \\
& SD & 46.0 & 29 & 0.1 \\
\hline Hypoendolithic & Avg & 564.9 & 409 & 4.6 \\
& SD & 31.7 & 32 & 1.0 \\
\hline
\end{tabular}

community (Fig. 4a). Cyanobacteria dominated the communities inhabiting all endolithic microhabitats; in the cryptoendolithic and chasmoendolithic communities, Cyanobacteria did not exceed $40 \%$ of the sequences, while in the hypoendolithic community they reached a relative abundance of $60 \%$ (Fig. 4a). Proteobacteria were the second most abundant phylum, contributing $\sim 30 \%$ of the sequences in the cryptoendolithic and chasmoendolithic communities and less than a half in the hypoendolithic community $(13 \%)$. The relative abundance of Actinobacteria was even across all microhabitats, never exceeding $10 \%$ of the sequence reads. Gemmatimonadetes relative abundance showed differences across microhabitats representing $7 \%, 4.4 \%$ and $2.3 \%$ of sequences in the cryptoendolithic, chasmoendolithic and hypoendolithic communities, respectively (Fig. 4a). The phyla Bacteroidetes and Thermi also exhibited variation between the different endolithic communities, showing the higher relative abundance in the hypoendolithic $(8.2 \%)$ and cryptoendolithic $(4.9 \%)$ microhabitats. Firmicutes and Planctomycetes were also found in all three microhabitats at very low relative abundance $(0.003 \%$ and $0.002 \%)$. No archaeal OTUs were detected before or after the quality filtering of sequences during the processing of the samples.

The four main phyla constituted $\sim 80 \%$ of OTUs, clustered at $97 \%$ identity, across all microhabitats, which was quite different from the distribution of sequence reads (Fig. 4b). The three major phyla, Cyanobacteria, Proteobacteria and Actinobacteria, have similar OTU relative abundances across all three microhabitats $(25 \%, 32 \%$ and $21 \%$, respectively). The greatest difference between the distribution of the relative abundance of sequences and that of OTUs is observed for Cyanobacteria in the hypoendolithic community.

Compared to other microhabitats, this phylum showed the highest relative abundance in terms of sequences $(60.4 \%)$ but the lowest in terms of OTUs (21.9\%), thus revealing the high abundance of a very low number of cyanobacterial OTUs. Average Bray-Curtis distance confirmed that dissimilarity between microhabitats (CR-CH $=0.36, \mathrm{CR}-\mathrm{HE}=0.44, \mathrm{CH}$ $\mathrm{HE}=0.44)$ was higher than between replicates of the same (a)

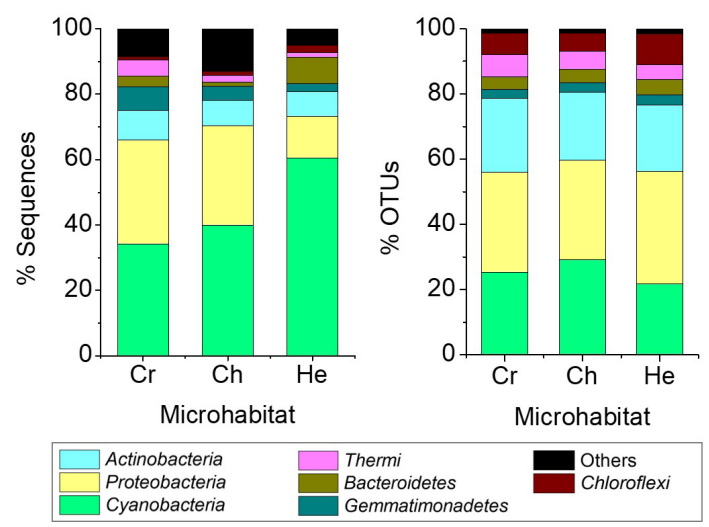

Figure 4. Average relative abundance of sequence reads (a) and OTUs at the $97 \%$ clustering cut-off (b) of major bacterial phyla (at least $1 \%$ across all samples) of microbial assemblages in the cryptoendolithic $(\mathrm{CR})$ chasmoendolithic $(\mathrm{CH})$ and hypoendolithic (HE) microhabitats of gypcrete.

microhabitat $(\mathrm{CR}=0.36, \mathrm{CH}=0.29, \mathrm{HE}=0.32)$. Adonis (analysis of variance using distance matrices) and ANOSIM (analysis of similarities) tests, performed with the three microhabitats categories (cryptoendolithic, chasmoendolithic and hypoendolithic), confirmed the statistical significance of the grouping $\left(R^{2}=0.38\right.$ with $p$ value $=0.014$ and $R^{2}=$ 0.48 with $p$ value $=0.003$ for adonis and ANOSIM, respectively).

\subsection{Cyanobacterial composition}

As the major component of the endolithic communities from the three described microhabitats, Cyanobacteria OTUs and isolates were studied in detail. A phylogenetic analysis of the 15 major cyanobacterial OTUs (relative abundance $>1 \%$ ) and 12 isolates revealed 6 main clusters supported by high bootstrap values (Fig. 5).

Most of the OTUs (9 out of 15) and isolates ( 8 out of 12) were assigned to the genus Chroococcidiopsis and were distributed in three clusters (I, III and V), each with representatives of Chroococcidiopsis isolates and clone sequences from various deserts. Cluster I had the highest number of sequences from this study: six of the Chroococcidiopsis strains (UAM801, UAM810, UAM802, UAM809, UAM800, UAM808) and four of the cyanobacterial OTUs (OTU1, OTU497, OTU8, OTU112). This cluster also included two reference Chroococcidiopsis sp. sequences of soils from the Atacama Desert (Patzelt et al., 2014). Cluster III included only one Chroococcidiopsis isolate (UAM805), three OTU sequences (OTU1772, OTU420 and OTU4), and reference sequences of Chroococcidiopsis sp. strains isolated from quartz hypolithic communities from hyper-arid Chinese deserts (Pointing et al., 2007) and from University Valley (Antarctica) (Cumbers and Rothschild, 2014). The last 


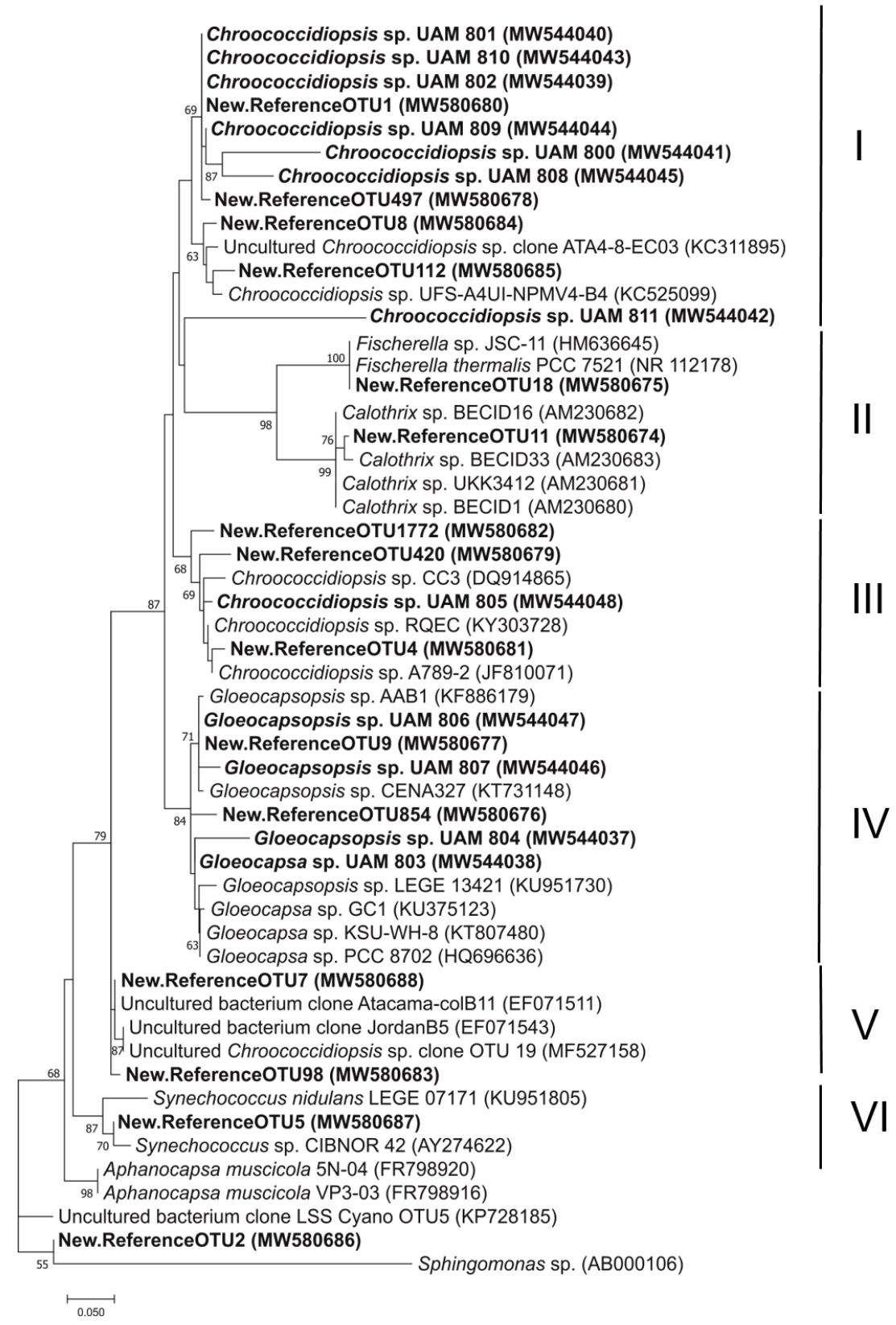

Figure 5. Maximum likelihood tree based on partial 16S rRNA sequences of Cyanobacteria OTUs above $1 \%$ relative abundance and cyanobacterial strains isolated from the three gypcrete microhabitats. Bold indicates sequences from this study. Scale bar indicates $5 \%$ sequence divergence.

Chroococcidiopsis sp. cluster, cluster V, had no sequences from isolates, two OTU sequences (OTU7 and OTU98), sequences from cloning libraries from two deserts, Atacama and Jordan deserts (Dong et al., 2007), and one Chroococcidiopsis sp. sequence from a Mediterranean biocrust (MuñozMartín et al., 2019).

Cluster II comprised cyanobacterial sequences belonging to the Nostocales order from the genera Fischerella and Calothrix to which OTU18 and OTU11 were respectively assigned. A total of six Cyanobacteria of this study were clus- tered with members of the genera Gloeocapsa and Gloeocapsopsis (order Chroococcales): four isolates (UAM806, UAM807, UAM804, UAM803) and two OTUs (OTU9, OTU854), forming cluster IV. Two reference sequences of Synechococcus together with OTU5 constituted Cluster VI.

Because of the low percentage identity of OTU2 with its closest relatives in the database $(<95 \%)$ (Table S2) and with our isolate sequences, it was not possible to provide an accurate taxonomical assignment for this OTU (Fig. 5). Hits were found between two of the isolates (Chroococcidiopsis 
UAM801 and Gloeocapsopsis UAM806) and two of the most abundant OTUs (OTU1 and OTU9, respectively).

Differential abundance analysis using the DESeq 2 test revealed that 9 out of 15 of the cyanobacterial OTUs were differentially abundant in the three microhabitats (Fig. 6). Both OTU11 (Calothrix sp.) and OTU18 (Fischerella sp), phylogenetically assigned to the Nostocales order, were significantly more abundant in the chasmoendolithic community $(3.8 \%$ and $1.5 \%$, respectively) than in cryptoendolithic and hypoendolithic communities ( $<0.4 \%$ for both OTUs) ( $p$ value $<0.01$ ). OTUs clustered with Gloeocapsa and Gloeocapsopsis (cluster IV), Synechococcus (cluster VI), and Chroococcidiopsis sp. from three clusters (I, III and V) showed significantly different abundances ( $p$ value $<0.001$ ) between the hypoendolithic community and that of the two communities from the upper side of the substrate (cryptoendolithic and chasmoendolithic). OTU8 (Chroococcidiopsis sp.) was the only one displaying a higher abundance in the hypoendolithic community, while OTU9 (Gloeocapsopsis sp.), OTU5 (Synechococcus sp.), OTU854 (Gloeocapsa sp.), and OTU1772 and OTU7 (Chroococcidiopsis sp.) had a higher abundance in the cryptoendolithic and chasmoendolithic communities. The unassigned cyanobacterial OTU2 was mostly found in the hypoendolithic community ( $p$ value $<0.0001)$ with an average relative abundance of more than $39 \%$ of the total community, while its relative abundance in the other two communities was $\sim 0.4 \%$.

\section{Discussion}

In this study, we characterized the microbial communities inhabiting gypcrete collected from the Monturaqui area (Preandean Depression), which is of particular interest due to its location in the hyper-arid zone of the Atacama Desert. While endolithic colonization of the gypsum crust and gypcrete in this area has previously been studied (Dong et al., 2007; DiRuggiero et al., 2013; Wierzchos et al., 2015; Meslier et al., 2018), this is the first work in which cryptoendolithic, chasmoendolithic and hypoendolithic communities have been characterized separately. The novelty of this study lies in the consideration of two different EMCs inhabiting two endolithic microhabitats located in the upper part of the substrate and in the description of the structure and composition of the hypoendolithic microhabitat and its endolithic community, located at the bottom part of the substrate.

The Monturaqui region, located in the Preandean Depression of the Atacama Desert has been found to harbour two different substrates colonized by microbial communities, namely gypcrete (Wierzchos et al., 2015) and ignimbrite, a volcanic rock (Wierzchos et al., 2013). Both substrates show endolithic colonization and a lack of epilithic colonization (rock surface colonization). The absence of this second type of colonization in any substrates from the Monturaqui region may be explained by the extremely arid microclimate of this area, including low relative humidity, high fluctuation of air and surface temperature, extremely high solar irradiation, and scarce precipitation (Wierzchos et al., 2015). Monturaqui has been described as a hyper-arid area, showing an aridity index of 0.0075 (Wierzchos et al., 2013), based on the ratio of mean annual precipitation $(P)$ and potential evapotranspiration rate $(\mathrm{PET})(\mathrm{P} / \mathrm{PET})$, up to 1 order of magnitude lower than the established limit (Nienow 2009) for the classification of hyper-arid regions (0.05). Specific measurements of surface temperature for gypcrete revealed values close to $70{ }^{\circ} \mathrm{C}$. This value was detected at the zenith, when microbial communities are desiccated and metabolically inactive (Cockell et al., 2008). The temperature within the endolithic habitats is expected to be close to that in the rock surface as shown by Wierzchos et al. (2012a) for halite endolithic microhabitats. The combination of these environmental conditions has led to the avoidance of epilithic colonization in favour of endolithic colonization.

Potential endolithic habitability is tightly linked to the porosity of a lithic substrate because the distribution and size of pores are often directly related to the substrate's water retention capacity (Cámara et al., 2014; Herrera et al., 2009; Matthes et al., 2001; Omelon 2008; Pointing et al., 2009; Meslier et al., 2018). Porosity in gypcrete allows microbial communities to survive in different microhabitats, providing sufficient space for the communities while receiving enough light and having enough water to metabolize and grow. The porous network of gypcrete restricts water loss by rapid evaporation and helps its retention by capillary forces acting in small capillary-like pores. The inner architecture of gypcrete allows for the habitability of three different locations inside the substrate. The CT-scan and SEM-BSE images from this work showed that all three types of microhabitats shared a vertical axis of morphology with vertical cracks constituting the chasmoendolithic $(\mathrm{CH})$ microhabitat, and capillarylike pores constitute the cryptoendolithic (CR) and hypoendolithic (HE) microhabitats. This capillary-like pore architecture found in the CR microhabitat could be explained by the progressive substrate dissolution due to scarce rains and by the water retained and condensed within the micropores, as it occurs in halite endolithic microhabitats (Wierzchos et al., 2012a). The observed HE microhabitat architecture supports the proposal of Wierzchos et al. (2015), in which the authors described the presence of a dense crust delimiting the bottom part of the HE microhabitat. This structure reveals different dissolving and crystallization processes of the gypsum following the water displacement from the surface to the bottom of the rock (gravity flow). This water gravity flow gives rise to the cave-shaped pores, thus providing this HE microhabitat with a hard permeable bottom gypsum layer.

The larger distance between the HE microhabitat and the top surface microhabitats $\mathrm{CR}$ and $\mathrm{CH}$ might be thought of as a limiting factor for the development of HE communities, especially in terms of water availability. However, the location of the HE microhabitat at the bottom of the rock could reduce 


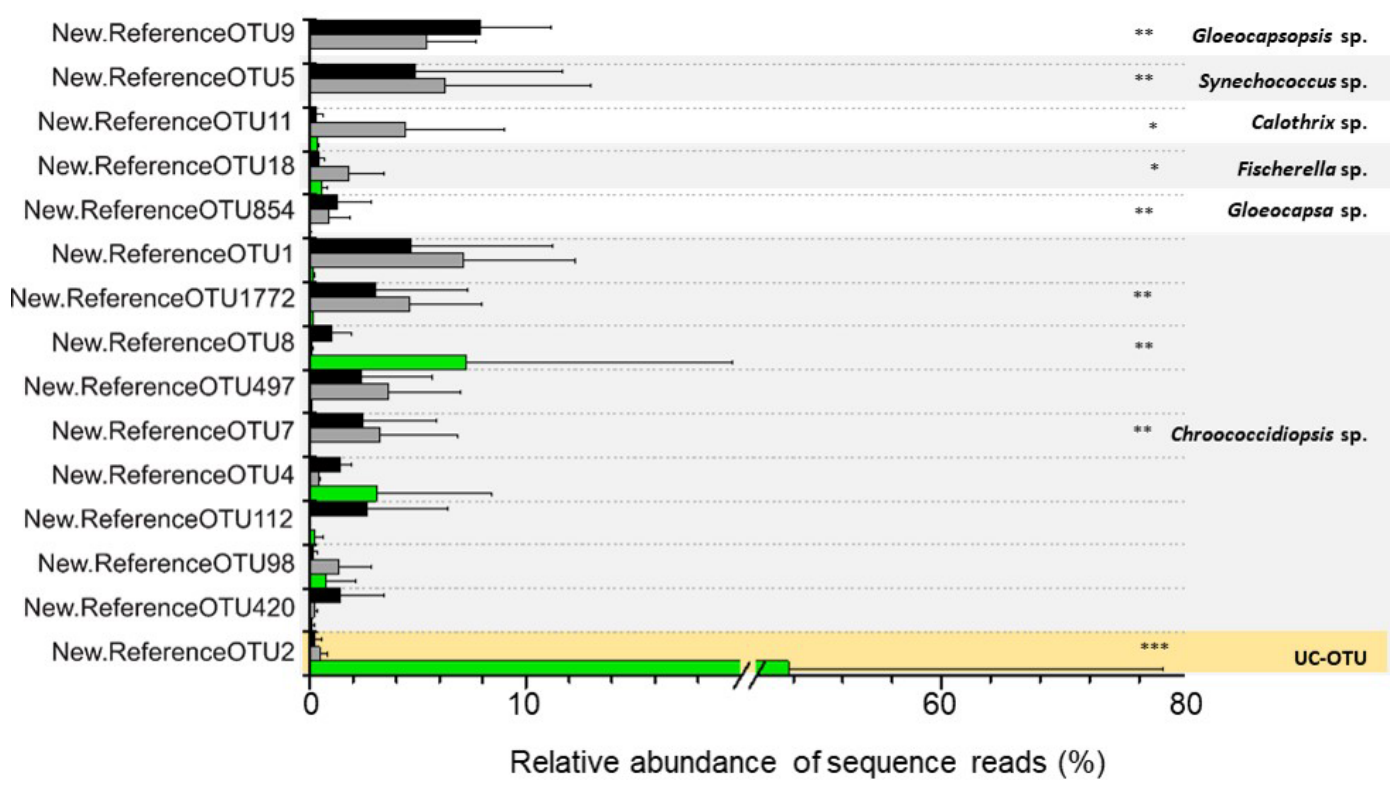

Figure 6. Differentially abundant cyanobacterial OTUs across the three microhabitats are represented by * (Diff-OTUs, $p$ value $<0.01 \mathrm{CH} / \mathrm{CR}-\mathrm{HE}$ ), ${ }^{* *}$ (Diff-OTUs, $p$ value $<0.001 \mathrm{HE} / \mathrm{CR}-\mathrm{CH}$ ) and ${ }^{* * *}$ (Diff-OTUs, $p$ value $<0.0001 \mathrm{HE} / \mathrm{CR}-\mathrm{CH}$ ). UC-OTU represents unclassified cyanobacterial OTU. Only sequences $>1 \%$ relative abundances were used. In the figure, black bars represent CR, grey bars represent $\mathrm{CH}$ and green bars represent $\mathrm{HE}$.

water losses due to evaporation processes. Thus, the microcave structures we observed in the HE microhabitat might retain liquid water for longer times, leading to cyanobacterial growth.

The structural characteristics of the crypto- and chasmoendolithic microhabitats, located at the top of the substrate, also allow access to water for the EMCs. Within the CR microhabitat, the labyrinth of pores directly or indirectly connected to the surface may act as cavities where water might be retained, condensed and also be present in the form of saturated water vapour (high $\mathrm{RH}$ ) through the substrate and be available to the microbial communities. Additionally, the presence of sepiolite inclusions improves water retention in those pores, as previously described (Wierzchos et al., 2015; Meslier et al., 2018), leading to lower rates of water loses by evaporation and gravitational forces. In contrast, the $\mathrm{CH}$ microhabitat provides direct access to rainfall liquid and dewfall water for its community, via its fissure and cracks, while at the same time lowering water retention capacity by higher evaporation rates and losing liquid water by percolation through the rock.

Microbial communities inhabiting all three microhabitats were found in the form of large aggregates and were often embedded in an EPS matrix. These characteristics are closely linked to survival strategies under harsh environmental conditions related to low water and nutrient availability (Billi, 2009; Wright et al., 2005). Since water is the most limiting factor for the development of microbial communities inhabiting endolithic microhabitats of gypcrete, it is the component on which adaptive strategies are primarily focused. EPS is an essential adaptation strategy against hyper-aridity due to its role in hydration and dehydration processes in lithobiontic communities, as previously observed in Antarctic deserts (de los Ríos et al., 2007) and the Atacama Desert (Dong et al., 2007; Wierzchos et al., 2011, 2015; Crits-Christoph et al., 2016). The aggregate-like structure of these communities composed of Cyanobacteria and heterotrophic bacteria also helps their survival against drought, since dead cells could provide physical protection against desiccation processes (Postgate, 1967; Roszak and Colwell, 1987; Billi, 2009; de los Ríos et al., 2004). In the case of the CR community, a special strategy against dryness was observed in this work, since microorganisms were located close to the sepiolite, as previously reported concerning gypcrete endolithic communities (Wierzchos et al., 2015; Meslier et al., 2018). EPS and dead cells taking part in the aggregates can also act as a nutrient reservoir in such an oligotrophic environment, since low amounts of water-soluble ions were previously detected in the MTQ gypcrete (Meslier et al., 2018).

The absence of significant differences in diversity metrics between the three EMCs of gypcrete is in accordance with the diversity values of previously reported EMCs in the Atacama Desert (reviewed in Casero et al., 2020). At a phylum level, the community was composited of three main dominant phyla, Cyanobacteria, Proteobacteria and Actinobacteria (Fig. 4), as in other EMCs of the Atacama Desert (Wierzchos et al., 2015; Meslier et al., 2018; Dong et al., 2007). However, a switch in the Proteobacteria and Actinobacteria 
relative abundances was found compared to gypcrete cryptoendolithic communities previously described (Meslier et al., 2018). That difference is presumably associated with different DNA extraction methods and the inherent associated biases. While the three types of gypcrete microhabitats are exposed to the same climatic conditions, we suggest that differences in micro-architectures resulted in drastically different sets of characteristics for water retention discussed previously: CR counts on water capillary porous condensation and sepiolite water absorption properties, $\mathrm{CH}$ has easier access to liquid water, and HE suffers less water loss.

While the communities from the three microhabitats had similar alpha diversity metrics, we found the composition of these communities was statistically different, which is supported by the relative abundance of the main phyla, Cyanobacteria, Proteobacteria and Actinobacteria, across the microhabitats distributed differentially, exhibiting differences between the $\mathrm{CR}$ and $\mathrm{CH}$ communities as compared to the HE community, especially regarding cyanobacterial OTUs. This notable difference in the relative abundance of Cyanobacteria could be related to the particular resources of the phototrophic community. The differential access to solar irradiance could explain the contrast between cyanobacterial proportions on both sides, at the top $(\mathrm{CR}$ and $\mathrm{CH})$ and bottom (HE) of the substrate. Thus, an update to the proposal by Wierzchos et al. (2018) is here suggested, in which a causal link is evoked to explain the higher abundances of phototrophs as opposed to heterotrophs in EMCs, which has been observed previously (Robinson et al., 2015; DiRuggiero et al., 2013; Wierzchos et al., 2015; Meslier et al., 2018). According to that work (Wierzchos et al., 2018), the scarcity of water was suggested to cause a lower metabolic activity in phototrophs, thus leading to lower support of the heterotrophic community. However, in this scenario, light intensity should also be considered a crucial factor in understanding the differences between the composition of top and bottom EMCs, since the HE community has notably lower access to sun radiation. Recently, the light intensity as a driving factor of spatial heterogeneity within halite endolithic microbial communities was reported by Uritskiy et al. (2020). Thus, for EMCs based on phototrophic microorganisms, a limitation to one of those resources essential for photosynthesis would further lead to low rates of $\mathrm{CO}_{2}$ fixation and, consequently, to a smaller heterotrophic community.

In contrast with results of Wierzchos et al. (2015) in gypcrete endolithic communities, no eukaryotic algae were found in microscopy nor molecular analyses, with Cyanobacteria being the phototrophic phylum observed in all gypcrete endolithic microhabitats. While we found multiple phylotypes of Cyanobacteria among the gypcrete microhabitats, most of them belonged to the genus Chroococcidiopsis. Several strains of this genus have previously been described in EMCs from both hot and cold deserts (Friedmann, 1980) as a result of their capacity to cope with extreme environmental conditions (Billi et al., 2011; Verseux et al., 2017).
Further supporting the different micro-environmental conditions and community composition between the top CR and $\mathrm{CH}$ habitats and the bottom HE habitat was the discovery of an unclassified cyanobacterial OTU (UC-OTU, "New.ReferenceOTU2"), which was almost exclusive to the HE microhabitat and the phylogenetic distance of the hypoendolithic Chroococcidiopsis UAM811 strain with the different Chroococcidiopsis clusters. Regarding the so-called UC-OTU, although the low percentage of sequence similarity did not allow for an accurate taxonomical assignment, its closest relatives ( $\sim 94 \%$ sequence identity for $450 \mathrm{nt}$ of the 16S rRNA gene) were from habitats where light is the limiting factor for photosynthesis such as a pinnacle mat at $10 \mathrm{~m}$ depth from a sinkhole (Hamilton et al., 2017) and groundwater sample from a tectonically formed cavern (Table S2). Both observations, the inability to identify the UC-OTU and the phylogenetic position of the UAM811 strain, highlight the importance of greater efforts in terms of isolation and characterization of cyanobacteria, especially from these environments.

The differential distribution of key members of these EMCs among microhabitats in the same lithic substrate and the same piece of rock, as their primary producers, reveals an "environmental filtering" process (Kraft et al., 2015). This concept focuses on the relationship between an organism and the environment, recognizing that not all organisms will be able to establish themselves successfully and persist in all abiotic conditions. Thus, in this scenario, the abiotic conditions linked to the architecture and location of the endolithic microhabitat would force the development of community assemblages highly specialized to small-scale differences, thereby exhibiting a micro-biogeographical behaviour.

Our work answers the hypothesis that there are certain differences in the structure of endolithic microbial communities among crypto-, chasmo- and hypoendolithic habitats. Considering that the external climatic regime was the same for the studied pieces of rock, our results have shown that the structure of these microbial communities was different among endolithic habitats. Following the definition of microhabitat architecture by Wierzchos et al. (2015), we can distinguish different architectures of the substrate within different endolithic microhabitats. In this context, our work suggests that distinct features of microhabitat architecture that have an influence on micro-environmental variables at the microscale would shape microbial community structure.

However, we are aware that more "micro-biogeographic" studies should be done with other endolithic microhabitats from the Atacama Desert and elsewhere. These may show that gypcrete is not a peculiar case where differences in the architecture of a microhabitat play an essential role in shaping the diversity and composition of endolithic microbial communities. 


\section{Conclusions}

This study is the first to address differences between microbial communities inhabiting three differentiated endolithic microhabitats within the same lithic substrate. In this study, liquid water availability was proposed to be a driver of community composition, because the specific architectural features of each microhabitat facilitated water input and retention in different ways. Water, light and $\mathrm{CO}_{2}$ are indispensable resources for photosynthetic activity. Thus, we support the cause and effect relationship where the restriction of these resources may affect the proportion of phototrophic and heterotrophic components in the EMCs as proposed by previous works (Robinson et al., 2015; Wierzchos et al., 2018 and Meslier et al., 2018).

The genus Chroococcidiopsis displayed a variety of strains distributed among all microhabitats, proving its high capacity to effectively colonize endolithic microhabitats under polyextreme conditions. Nevertheless, the presence of a singular cyanobacterial OTU stresses the need for additional efforts in cyanobacterial characterization from these extreme environments.

Findings from this work reveal the importance of using an appropriate scale for the study of microbial communities. Indeed, we found that the microstructural and microarchitectural features of the endolithic habitats were key factors in determining the composition of endolithic microbial communities. Thus, this study suggests a cautious use of "macro-environmental" parameters in characterizing differences between endolithic communities from different deserts or substrates. Our results point to the need for a more thorough description of the micro-environmental conditions that directly exert an effect on microbial assemblages: light, water and $\mathrm{CO}_{2}$. Therefore, once the relationship between factors affecting the absence and/or presence of certain taxa is identified, the actual environmental filtering in these microhabitats could be described in more detail, and it will be possible to draw conclusions on the interactions and specific roles of the different members in the community and their microbiogeography.

Data availability. All the sequencing data sets generated in this study have been submitted to the US National Center for Biotechnology Information (NCBI) Sequence Read Archive (SRA) and can be found under the BioProject ID PRJNA637482.

Supplement. The supplement related to this article is available online at: https://doi.org/10.5194/bg-18-993-2021-supplement.

Author contributions. MCC and JW designed and performed the research. JW conceived the original project. MCC, JW and OA carried out the sampling. MCC, JW and AQ wrote the article. MCC, JW and CA performed the microscopy. TK contributed to CT-scan analysis. MCC, VMA and JDR contributed to the molecular data, analysis, and performed the sequencing. All authors contributed to editing and revising the article and approved this version for submission.

Competing interests. The authors declare that they have no conflict of interest.

Acknowledgements. The work of MCC was supported by grant BES 2014-069106 from the Spanish Ministry of Science and Innovation (MCINN). The MNCN-CSIC, Madrid, Spain, is acknowledged for microscopy services.

Financial support. This research has been supported by the MCIU/AEI (Spain) and FEDER (UE) (grant no. PGC2018094076-B-I00), the NSF (grant no. DEB1556574), and NASA (grant no. NNX15AP18G).

We acknowledge support of the publication fee by the CSIC Open Access Publication Support Initiative through its Unit of Information Resources for Research (URICI).

Review statement. This paper was edited by Andreas Richter and reviewed by three anonymous referees.

\section{References}

Azua-Bustos, A., Urrejola, C., and Vicuña, R.: Life at the dry edge: microorganisms of the Atacama Desert., FEBS Lett., 586, 29392945, https://doi.org/10.1016/j.febslet.2012.07.025, 2012.

Azua-Bustos, A., Caro-Lara, L., and Vicuña, R.: Discovery and microbial content of the driest site of the hyperarid Atacama Desert, Chile, Environ. Microbiol. Rep., 7, 388-394, https://doi.org/10.1111/1758-2229.12261, 2015.

Baas-Becking, L. G. M.: Geobiologie of inleiding tot de milieukunde, edited by: Van Stockum, W. P. and Zoon, N. V., The Hague, Netherlands, 1934.

Bass, D. and Boenigk, J.: Everything is everywhere: a twenty-first century de-/reconstruction with respect to protists, Biogeogr. Microsc. Org., 88-110, https://doi.org/10.1017/CBO9780511974878.007, 2011.

Becerra-Absalón, I., Muñoz-Martín, M., Á., Montejano, G., and Mateo, P.: Differences in the cyanobacterial community composition of biocrusts from the drylands of Central Mexico, Are there endemic species?, Front. Microbiol, 10, 937, https://doi.org/10.3389/fmicb.2019.00937, 2019.

Billi, D., Friedmann, E. I., Hofer, K. G., Caiola, M. G., and Ocampo-Friedmann, R.: Ionizing-radiation resistance in the desiccation-tolerant cyanobacterium Chroococcidiopsis, Appl. Environ. Microbiol., 66, 1489-1492, https://doi.org/10.1128/aem.66.4.1489-1492.2000, 2000.

Billi, D.: Subcellular integrities in Chroococcidiopsis sp. CCMEE 029 survivors after prolonged desiccation revealed by molecular 
probes and genome stability assays, Extremophiles, 13, 49-57, https://doi.org/10.1007/s00792-008-0196-0, 2009.

Billi, D., Viaggiu, E., Cockell, C. S., Rabbow, E., Horneck, G., and Onofri, S.: Damage escape and repair in dried Chroococcidiopsis spp. from hot and cold deserts exposed to simulated space and Martian conditions, Astrobiology, 11, 65-73, https://doi.org/10.1089/ast.2009.0430, 2011.

Cámara, B., Suzuki, S., Nealson, K. H., Wierzchos, J., Ascaso, C., Artieda, O., and de los Ríos, A.: Ignimbrite textural properties as determinants of endolithic colonization patterns from hyper-arid Atacama Desert, Int. Microbiol, 17, 235-247, https://doi.org/10.2436/20.1501.01.226, 2014.

Caporaso, J. G., Kuczynski, J., Stombaugh, J., Bittinger, K., Bushman, F. D., Costello, E. K., Fierer, N., Pena, A. G., Goodrich, J. K., and Gordon, J. I.: QIIME allows analysis of highthroughput community sequencing data, Nat. Methods, 7, 335336, https://doi.org/10.1038/nmeth.f.303, 2010.

Casero, M. C., Ballot, A., Agha, R., Quesada, A., and Cirés, S.: Characterization of saxitoxin production and release and phylogeny of sxt genes in paralytic shellfish poisoning toxinproducing Aphanizomenon gracile, Harmful Algae, 37, 28-37, https://doi.org/10.1016/j.hal.2014.05.006, 2014.

Casero, M. C., Meslier, V., Wierzchos, J., and DiRuggiero, J.: Preandean Atacama Desert Endolithic Microbiology, in Microbial Ecosystems in Central Andes Extreme Environments, edited by: Farías, M., Springer International Publishing, Cham., https://doi.org/10.1007/978-3-030-36192-1_4, 51-71, 2020.

Chao, A.: Nonparametric estimation of the number of classes in a population, Scan. J. Stat., 265-270, 1984.

Cockell, C. S., McKay, C. P., Warren-Rhodes, K. and Horneck, G.: Ultraviolet radiation-induced limitation to epilithic microbial growth in arid deserts - Dosimetric experiments in the hyperarid core of the Atacama Desert, J. Photochem. Photobiol. B Biol., 90, 79-87, https://doi.org/10.1016/j.jphotobiol.2007.11.009, 2008.

Cockell, C. S., Schuerger, A. C., Billi, D., Friedmann, E. I., and Panitz, C.: Effects of a simulated martian UV flux on the cyanobacterium, Chroococcidiopsis sp. 029, Astrobiology, 5, 127-140, https://doi.org/10.1089/ast.2005.5.127, 2005.

Cole, J. R., Wang, Q., Fish, J. A., Chai, B., McGarrell, D. M., Sun, Y., Brown, C. T., Porras-Alfaro, A., Kuske, C. R., and Tiedje, J. M.: Ribosomal Database Project: data and tools for high throughput rRNA analysis, Nucleic Acids Res., 42, 633642, https://doi.org/10.1093/nar/gkt1244, 2014.

Cordero, R. R., Seckmeyer, G., Damiani, A., Riechelmann, S., Rayas, J., Labbe, F., and Laroze, D.: The world's highest levels of surface UV, Photochem. Photobiol. Sci., 13, 70-81, https://doi.org/10.1039/C3PP50221J, 2014.

Cordero, R. R., Damiani, A., Jorquera, J., Sepúlveda, E., Caballero, M., Fernandez, S., Feron, S., Llanillo, P. J., Carrasco, J., and Laroze, D.: Ultraviolet radiation in the Atacama Desert, Antonie Van Leeuwenhoek, 111, 1301-1313, https://doi.org/10.1007/s10482-018-1075-z, 2018.

Crits-Christoph, A., Robinson, C. K., Ma, B., Ravel, J., Wierzchos, J., Ascaso, C., Artieda, O., Souza-Egipsy, V., Casero, M. C., and DiRuggiero, J.: Phylogenetic and functional substrate specificity for endolithic microbial communities in hyper-arid environments, Front. Microbiol., 7, 301, https://doi.org/10.3389/fmicb.2016.00301, 2016.
Cumbers, J. and Rothschild, L. J.: Salt tolerance and polyphyly in the cyanobacterium Chroococcidiopsis (Pleurocapsales), J. Phycol., 50, 472-482, https://doi.org/10.1111/jpy.12169, 2014.

de los Ríos, A., Wierzchos, J., Sancho, L. G., and Ascaso, C.: Exploring the physiological state of continental Antarctic endolithic microorganisms by microscopy, FEMS Microbiol. Ecol., 50, 143-152, https://doi.org.10.1016/j.femsec.2004.06.010, 2004.

de los Ríos, A., Grube, M., Sancho, L. G., and Ascaso, C.: U1trastructural and genetic characteristics of endolithic cyanobacterial biofilms colonizing Antarctic granite rocks, FEMS Microbiol. Ecol., 59, 386-395, https://doi.org/10.1111/j.15746941.2006.00256.x, 2007.

de los Ríos, A., Valea, S., Ascaso, C., Davila, A., Kastovsky, J., McKay, C. P., Gómez-Silva, B., and Wierzchos, J.: Comparative analysis of the microbial communities inhabiting halite evaporites of the Atacama Desert, Int. Microbiol. Off. J. Spanish Soc. Microbiol., 13, 79-89, https://doi.org/10.2436/20.1501.01.113, 2010 .

de Wit, R. and Bouvier, T.: "Everything is everywhere, but, the environment selects"; what did Baas Becking and Beijerinck really say?, Environ. Microbiol., 8, 755-758, https://doi.org/10.1111/j.1462-2920.2006.01017.x, 2006.

DiRuggiero, J., Wierzchos, J., Robinson, C. K., Souterre, T., Ravel, J., Artieda, O., Souza-Egipsy, V., and Ascaso, C.: Microbial colonisation of chasmoendolithic habitats in the hyper-arid zone of the Atacama Desert, Biogeosciences, 10, 2439-2450, https://doi.org/10.5194/bg-10-2439-2013, 2013.

Dong, H., Rech, J. A., Jiang, H., Sun, H., and Buck, B. J.: Endolithic cyanobacteria in soil gypsum: Occurrences in Atacama (Chile), Mojave (United States), and Al-Jafr Basin (Jordan) Deserts, J. Geophys. Res.-Biogeo., J. Geophys. Res., 112, G02030, https://doi.org/10.1029/2006JG000385, 2007.

Edwards, U., Rogall, T., Blöcker, H., Emde, M., and Böttger, E. C.: Isolation and direct complete nucleotide determination of entire genes. Characterization of a gene coding for 16S ribosomal RNA, Nucleic Acids Res., 17, 7843-7853, https://doi.org/10.1093/nar/17.19.784, 1989.

Fontaneto, D. and Hortal, J.: Microbial biogeography: is everything small everywhere, Microb. Ecol. Theory Curr. Perspect. Caister Acad. Press. Norfolk, 87-98, 2012.

Friedmann, E. I.: Endolithic microbial life in hot and cold deserts, in: Limits of life, Springer, 33-45, https://doi.org/10.1007/97894-009-9085-2_3, 1980.

Hamilton, T. L., Welander, P. V, Albrecht, H. L., Fulton, J. M., Schaperdoth, I., Bird, L. R., Summons, R. E., Freeman, K. H., and Macalady, J. L.: Microbial communities and organic biomarkers in a Proterozoic-analog sinkhole, Geobiology, 15, 784-797, https://doi.org/10.1111/gbi.12252, 2017.

Herrera, A., Cockell, C. S., Self, S., Blaxter, M., Reitner, J., Thorsteinsson, T., Arp, G., Dröse, W., and Tindle, A. G.: A cryptoendolithic community in volcanic glass, Astrobiology, 9, 369381, https://doi.org/10.1089/ast.2008.0278, 2009.

Joshi, N. A. and Fass, J. N.: Sickle: A sliding-window, adaptive, quality-based trimming tool for FastQ files (Version 1.33) Software, 2011.

Kimura, M.: A simple method for estimating evolutionary rates of base substitutions through comparative studies of nucleotide sequences, J. Mol. Evol., 16, 111-120, https://doi.org/10.1007/BF01731581, 1980. 
Komárek, J., Kaštovský, J., Mareš, J., and Johansen, J. R.: Taxonomic classification of cyanoprokaryotes (cyanobacterial genera) 2014, using a polyphasic approach, Preslia, 86, 295-335, 2014.

Kraft, N. J. B., Adler, P. B., Godoy, O., James, E. C., Fuller, S., and Levine, J. M.: Community assembly, coexistence and the environmental filtering metaphor, Funct. Ecol., 29, 592-599, https://doi.org/10.1111/1365-2435.12345, 2015.

Kumar, S., Stecher, G., and Tamura, K.: MEGA7: molecular evolutionary genetics analysis version 7.0 for bigger datasets, Mol. Biol. Evol., 33, 1870-1874, https://doi.org/10.1093/molbev/msw054, 2016.

Lepère, C., Wilmotte, A., and Meyer, B.: Molecular diversity of Microcystis strains (Cyanophyceae, Chroococcales) based on 16S rDNA sequences, Syst. Geogr. Plants, 70, 275-283, https://doi.org/10.2307/3668646, 2000.

Loza, V., Perona, E., and Mateo, P.: Molecular fingerprinting of cyanobacteria from river biofilms as a water quality monitoring tool, Appl. Environ. Microbiol., 79, 1459-1472, https://doi.org/10.1128/AEM.03351-12, 2013.

Matthes, U., Turner, S. J., and Larson, D. W.: Light attenuation by limestone rock and its constraint on the depth distribution of endolithic algae and cyanobacteria, Int. J. Plant Sci., 162, 263-270, https://doi.org/10.1086/319570, 2001.

McKay, C. P., Friedmann, E. I., Gómez-Silva, B., CáceresVillanueva, L., Andersen, D. T., and Landheim, R.: Temperature and moisture conditions for life in the extreme arid region of the Atacama Desert: four years of observations including the El Nino of 1997-1998, Astrobiology, 3, 393-406, https://doi.org/10.1089/153110703769016460, 2003.

Meslier, V., Casero, M. C., Dailey, M., Wierzchos, J., Ascaso, C., Artieda, O., McCullough, P. R., and DiRuggiero, J.: Fundamental drivers for endolithic microbial community assemblies in the hyperarid Atacama Desert, Environ. Microbiol., 20, 1765-1781, https://doi.org/10.1111/1462-2920.14106, 2018.

Muñoz-Martín, M. Á., Becerra-Absalón, I., Perona, E., FernándezValbuena, L., Garcia-Pichel, F., and Mateo, P.: Cyanobacterial biocrust diversity in Mediterranean ecosystems along a latitudinal and climatic gradient, New Phytol., 221, 123-141, https://doi.org/10.1111/nph.15355, 2019.

Nienow, J. A.: Extremophiles: Dry Environments (including Cryptoendoliths), edited by: Schaechter, M., Academic Press, Oxford, 159-173, https://doi.org/10.1016/B978-012373944-5.00277-7, 2009.

O'Malley, M. A.: "Everything is everywhere: but the environment selects": ubiquitous distribution and ecological determinism in microbial biogeography, Stud. Hist. Philos. Biol. Biomed. Sci., 39, 314-325, https://doi.org/10.1016/j.shpsc.2008.06.005, 2008.

Omelon, C. R.: Endolithic microbial communities in polar desert habitats, Geomicrobiol. J., 25, 404-414, 2008.

Patzelt, D. J., Hodač, L., Friedl, T., Pietrasiak, N., and Johansen, J. R.: Biodiversity of soil cyanobacteria in the hyper-arid Atacama Desert, Chile, J. Phycol., 50, 698-710, https://doi.org/10.1111/jpy.12196, 2014.

Pointing, S. B. and Belnap, J.: Microbial colonization and controls in dryland systems, Nat. Rev. Microbiol., 10, 551-562, https://doi.org/10.1038/nrmicro2831, 2012.

Pointing, S. B., Warren-Rhodes, K. A., Lacap, D. C., Rhodes, K. L., and McKay, C. P.: Hypolithic community shifts occur as a result of liquid water availability along environmental gradients in China's hot and cold hyperarid deserts, Environ Microbiol., 9, 414-424, https://doi.org/10.1111/j.1462-2920.2006.01153.x, 2007.

Pointing, S. B., Chan, Y., Lacap, D. C., Lau, M. C. Y., Jurgens, J. A., and Farrell, R. L.: Highly specialized microbial diversity in hyper-arid polar desert, P. Natl. Acad. Sci. USA, 106, 19964 19969, https://doi.org/10.1073/pnas.0908274106, 2009.

Postgate, J. R.: Viability measurements and the survival of microbes under minimum stress, in: Advances in microbial physiology, Elsevier, 1, 1-23, https://doi.org/10.1016/S0065-2911(08)60248-9, 1967.

Rippka, R., Deruelles, J., Waterbury, J. B., Herdman, M., and Stanier, R. Y.: Generic assignments, strain histories and properties of pure cultures of cyanobacteria, Microbiology, 111, 1-61, https://doi.org/10.1099/00221287-111-1-1, 1979.

Robinson, C. K., Wierzchos, J., Black, C., Crits-Christoph, A., Ma, B., Ravel, J., Ascaso, C., Artieda, O., Valea, S., and Roldán, M.: Microbial diversity and the presence of algae in halite endolithic communities are correlated to atmospheric moisture in the hyperarid zone of the Atacama Desert, Environ. Microbiol., 17, 299315, https://doi.org/10.1111/1462-2920.12364, 2015.

Roszak, D. B. and Colwell, R. R.: Survival strategies of bacteria in the natural environment, Microbiol. Rev., 51, 365-379, 1987.

Rothschild, L. J. and Mancinelli, R. L.: Life in extreme environments, Nature, 409, 1092-1101, https://doi.org/10.1038/35059215, 2001.

Shannon, C. E.: A mathematical theory of communication, The Bell system technical journal, 27, 379-423, 1948.

Thompson, J. D., Higgins, D. G., and Gibson, T. J.: CLUSTAL W: improving the sensitivity of progressive multiple sequence alignment through sequence weighting, position-specific gap penalties and weight matrix choice, Nucleic Acids Res., 22, 46734680, https://doi.org/10.1093/nar/22.22.4673, 1994.

van der Gast, C. J.: Microbial biogeography: the end of the ubiquitous dispersal hypothesis?, Environ. Microbiol., 17, 544-546, https://doi.org/10.1111/1462-2920.12635, 2015.

Uritskiy, G., Getsin, S., Munn, A., Gomez-Silva, B., Davila, A., Glass, B., Taylor, J., and DiRuggiero, J.: Halophilic microbial community compositional shift after a rare rainfall in the Atacama Desert, ISME J., 13, 2737-2749, https://doi.org/10.1038/s41396-019-0468-y, 2019.

Uritskiy, G., Munn, A., Dailey, M., Gelsinger, D. R., Getsi, S., Davila, A., McCullough, P. R., Taylor, J., and DiRuggiero, J.: Environmental factors driving spatial heterogeneity in desert halophile microbial communities, Front. Microbiol. 11, 578669, https://doi.org/10.3389/fmicb.2020.578669, 2020.

Verseux, C., Baqué, M., Cifariello, R., Fagliarone, C., Raguse, M., Moeller, R., and Billi, D.: Evaluation of the resistance of Chroococcidiopsis spp. to sparsely and densely ionizing irradiation, Astrobiology, 17, 118-125, https://doi.org/10.1089/ast.2015.1450, 2017.

Vítek, P., Ascaso, C., Artieda, O., and Wierzchos, J.: Raman imaging in geomicrobiology: endolithic phototrophic microorganisms in gypsum from the extreme sun irradiation area in the Atacama Desert, Anal. Bioanal. Chem., 408, 4083-4092, https://doi.org/10.1007/s00216-016-9497-9, 2016.

Walker, J. J. and Pace, N. R.: Endolithic microbial ecosystems, Annu. Rev. Microbiol., 61, 331-347, 
https://doi.org/10.1146/annurev.micro.61.080706.093302, 2007.

Wierzchos, J., Casero, M. C., Artieda, O., and Ascaso, C.: Endolithic microbial habitats as refuges for life in polyextreme environment of the Atacama Desert, Curr. Opin. Microbiol., 43, 124-131, https://doi.org/10.1016/j.mib.2018.01.003, 2018.

Wierzchos, J. and Ascaso, C.: Application of back-scattered electron imaging to the study of the lichen-rock interface, J. Microsc., 175, 54-59, https://doi.org/10.1111/j.13652818.1994.tb04787.x, 1994.

Wierzchos, J., Cámara, B., de Los Rios, A., Davila, A. F., Sánchez Almazo, I. M., Artieda, O., Wierzchos, K., Gomez-Silva, B., McKay, C., and Ascaso, C.: Microbial colonization of Ca-sulfate crusts in the hyperarid core of the Atacama Desert: implications for the search for life on Mars, Geobiology, 9, 44-60, https://doi.org/10.1111/j.1472-4669.2010.00254.x, 2011.

Wierzchos, J., Davila, A. F., Sánchez-Almazo, I. M., Hajnos, M., Swieboda, R., and Ascaso, C.: Novel water source for endolithic life in the hyperarid core of the Atacama Desert, Biogeosciences, 9, 2275-2286, https://doi.org/10.5194/bg-9-2275-2012, 2012a.
Wierzchos, J., de los Ríos, A., and Ascaso, C.: Microorganisms in desert rocks: the edge of life on Earth, Int Microbiol., 15, 173183, https://doi.org/10.2436/20.1501.01.170, 2012b.

Wierzchos, J., Davila, A. F., Artieda, O., Cámara-Gallego, B., de los Ríos, A., Nealson, K. H., Valea, S., García-González, M. T., and Ascaso, C.: Ignimbrite as a substrate for endolithic life in the hyper-arid Atacama Desert: Implications for the search for life on Mars, Icarus, 224, 334-346, https://doi.org/10.1016/j.icarus.2012.06.009, 2013.

Wierzchos, J., DiRuggiero, J., Vítek, P., Artieda, O., SouzaEgipsy, V., Skaloud, P., Tisza, M., Davila, A. F., Vílchez, C., and Garbayo, I.: Adaptation strategies of endolithic chlorophototrophs to survive the hyperarid and extreme solar radiation environment of the Atacama Desert, Front. Microbiol., 6, 934, https://doi.org/10.3389/fmicb.2015.00934, 2015.

Wright, D. J., Smith, S., Joardar, V., Scherer, S., Jervis, J., Warren, A., Helm, R., and Potts, M.: UV Irradiation and Desiccation Modulate the Three-dimensional Extracellular Matrix of Nostoc commune (Cyanobacteria), J. Biol. Chem., 280, 40271-40281, https://doi.org/10.1074/jbc.M505961200, 2005. 